Jurnal Psikologi Malahayati, Volume 1, No.2, September 2019: 49-60

\title{
KECEMASAN PADA WANITA YANG TELAT MENIKAH DALAM PERSPEKTIF PERSON CENTERED \\ THERAPY
}

\author{
Renyep Proborini ${ }^{1}$, Gilang Sukma Lestari ${ }^{2}$, Khairani ${ }^{3}$ \\ 1, 2,3Fakultas Psikologi Universitas Muhammadiyah Lampung, rproborini66@gmail.com
}

\section{ABSTRACT: ANXIETY AMONG LATE MARRIED WOMEN IN PERSON CENTERED THERAPY PERSPECTIVE}

This study aim to find data about anxiety among late married women. Discussion about this problem will be based on Person Centered Therapy form Carl R Rogers. The method used in this study was a qualitative method with case study approach. The subject of this study was three unmarried women, 28-30 years old, live in Bandar Lampung. Data obtained by interview and observation. To improve data credibility, interviews were also conducted on the third parties pf each subject. The result of this study shows that anxiety found in women who get married late is varied from low, mideum, and high. As adult women who already have self-concept, the subjects choose and realize a number of experiences that are in accordance with themselves. If it does not match, it will be ignored or changed. The self finally forms the ideal self and self concept. Self-confidence and independence help the subject to accept the reality of the problem. Unconsciousness of experiences that are seen, heard and felt, can reduce anxiety in one side, but increased anxiety on the other side, because it is contrary to the reality.

\section{Keyword: Anxiety, Late Married Women, Person Centered Therapy}

Penelitian ini bertujuan untuk memperoleh data mengenai kecemasan yang dialami oleh wanita yang telat menikah. Pembahasan masalah ini akan dilandasi pendekatan teori Person Centered Therapy dari Carl R. Rogers. Metode penelitian yang digunakan adalah metode kualitatif dengan pendekatan studi kasus. Subyek penelitian adalah tiga orang wanita yang belum menikah, berusia 28-30 tahun yang tinggal di Bandarlampung. Pengumpulan data menggunakan metode wawancara dan observasi. Untuk lebih memperkuat kredibilitas data, maka dilakukan wawancara terhadap pihak ketiga dari masing-masing subyek. Hasil penelitian menunjukkan bahwa kecemasan karena telat menikah pada para subyek bervariasi dari level rendah, sedang dan tinggi. Sebagai wanita dewasa yang telah memiliki konsep diri, para subyek memilih dan menyadari sejumlah pengalamannya yang sesuai dengan diri. Bila tak sesuai maka akan diabaikan atau diubah. Diri akhirnya membentuk konsep diri dan diri ideal. Kepercayaan diri dan kemandirian membantu subyek untuk dapat menerima kenyataan mengenai permasalahannya. Ketidaksadaran terhadap pengalaman yang dilihat, didengar dan dirasai, satu sisi dapat meredam kecemasan namun di sisi lain mendorong meningkatnya kecemasan karena bertentangan dengan realita yang ada.

\section{Kata kunci: Kecemasan; Wanita Telat Menikah; Person Centered Therapy}

\section{PENDAHULUAN}

Pernikahan merupakan proses awal untuk membentuk keluarga. Keluarga adalah kelompok orang yang memiliki hubungan darah atau perkawinan (Kusdwiratri, 2011). Siklus kehidupan berkeluarga dimulai pada masa dewasa awal yaitu dengan meninggalkan rumah dan hidup sendiri, kemudian menikah dan membentuk keluarga. Berlanjut dengan memiliki anak, membesarkannya, hingga akhirnya keluarga di usia lanjut (Santrock, 2002). Pembentukan keluarga, memberikan konsekuensi yang besar berupa tanggungjawab atas peran yang dijalankan oleh seorang laki- 


\section{KECEMASAN PADA WANITA YANG TELAT MENIKAH DALAM PERSPEKTIF PERSON CENTERED THERAPY}

laki dan seorang wanita, yaitu sebagai suami/istri, sebagai orang tua, sebagai menantu dan sebagai anggota keluarga dari keluarga besar. Menikah merupakan kebutuhan yang muncul secara alamiah ketika ada dorongan untuk memenuhi kebutuhan seks, mendapatkan cinta dan kasih sayang dari lawan jenis. Kebutuhan ini semakin menguat ketika lingkungan social memiliki harapan terhadap kaum dewasa muda untuk menikah. Menikah, menunda menikah atau tidak menikah merupakan sebuah pilihan bagi sebagian kaum dewasa awal.

Ketentuan secara hukum di Indonesia mengenai usia menikah diatur dalam UU Perkawinan No.1 Tahun 1974, bagi wanita minimal usia 16 tahun, bagi laki-laki minimal 19 tahun (Fadlyana, Larasaty, 2009). Namun demikian, peninjauan mengenai kesiapan lakilaki dan wanita dalam menjalani peran sesudah menikah, baik sebagai suami-istri maupuan sebagai ayah-ibu, mendorong munculnya kampanye pendewasaan usia menikah yang diluncurkan oleh BKKBN. Usia ideal menikah bagi wanita 21 tahun dan bagi laki-laki 25 tahun (Ma'arif 2018). Agustian (2013) menyebutkan bahwa usia ideal untuk menikah bagi wanita antara 21-25 tahun karena pada usia ini organ reproduksi wanita telah berkembang matang dan secara psikologis lebih stabil, sehingga wanita lebih siap untuk memiliki anak. Sedangkan laki-laki, usia ideal adalah 25-28 tahun, yang mana pada usia tersebut laki-laki lebih matang secara fisik, emosi, social dan mandiri secara ekonomi. Berdasarkan program pemerintah serta penelitian tersebut maka dapat disimpulkan bahwa menikah lebih dari 25 tahun dapat dikategorikan telat menikah bagi wanita.

Telat menikah bagi perempuan di Indonesia memiliki latar belakang yang beragam, mulai dari belum menemukan pasangan yang cocok, tidak disetujui oleh orang tua, belum siap secara psikologis, belum siap secara financial, dan kesulitan mendapatkan pasangan. Ketika ada kebutuhan dan harapan untuk menikah, namun pada kenyataannya belum menikah, maka kondisi tersebut berpeluang menimbulkan kecemasan (Adhim, 2014).

Pendekatan Person Centered Therapy dari Carl Rogers (Feist \& Feist, 2010) menjelaskan bahwa kecemasan adalah kondisi yang tidak menyenangkan atau tekanan dari sumber yang tidak diketahui. Kecemasan muncul ketika individu menyadari atau sedikit menyadari akan inkongruensi yang dialaminya. Inkongruensi merupakan kondisi di mana ada perbedaaan antara diri ideal dengan konsep diri.

Menurut Rogers (dalam Anderson, 2001), setiap individu memiliki dua sub sistem dalam diri, yaitu konsep diri dan diri ideal. Konsep diri merupakan pengalaman seseorang yang disadari. Pembentukan konsep diri bermula dari adanya pengalaman organisme

Renyep Proborini, Fakultas Psikologi Universitas Muhammadiyah Lampung, Email: rproborinini66@gmail.com

Gilang Sukma Lestari, Fakultas Psikologi Universitas Muhammadiyah Lampung. Khairani, Fakultas Psikologi Universitas Muhammadiyah Lampung 


\section{KECEMASAN PADA WANITA YANG TELAT MENIKAH DALAM PERSPEKTIF PERSON CENTERED THERAPY}

dari individu, yaitu kesatuan antara apa yang dirasakan oleh badan berupa sensasi dan perubahan-perubahan fisik, serta apa yang dipikirkan. Selain itu pengalaman organisme tersebut sebagian ada yang tidak disadari dan sebagian disadari. Secara singkat pengalaman organisme adalah semua yang melibatkan fisik, kognitif, kesadaran dan ketidaksadaran. Sejumlah perubahan fisik dan kognitif yang dialami oleh individu, tidak selalu disadari. Sebagian yang disadari oleh individu kemudian diakui dan melekat menjadi identitas diri. Konsep diri merupakan penilaian terhadap diri sendiri yang terbentuk dari kesadarankesadaran tersebut.

Adapun pengalaman organisme yang tidak disadari, yang berbeda dengan konsep diri, dapat menimbulkan ketidaknyamanan atau inkongkruensi pada individu. Individu berusaha untuk mengatasinya untuk mendapatkan kenyamanan. Sejumlah cara yang dilakukan adalah mengubah atau mengabaikan pengalaman organisme tersebut agar sesuai dengan konsep diri (Anderson, 2001). Diri ideal merupakan pandangan seseorang terhadap diri sebagaimana yang diharapkannya. Diri ideal biasanya berkaitan dengan hal-hal yang positif yang ingin dimiliki atau dicapai oleh seseorang.

Konsep diri dan diri ideal pada umumnya akan berjarak. Diri ideal akan mendorong individu untuk mengubah sebagian diri agar mendekati atau sama dengan diri ideal.
Konsep diri yang berisi tentang kesadaran atas berbagai pengalaman, perlu diubah agar dapat mendekati diri ideal. Ketika terjadi perbedaan yang besar antara diri ideal dengan konsep diri, maka individu akan mengalami inkongkruen. Kesadaran yang muncul terhadap kondisi inkongruensi ini, yaitu individu menyadari bahwa keinginannya jauh dari kenyataan, akan memunculkan kecemasan.

Menikah merupakan satu kondisi yang diidamkan oleh individu dewasa, yang dalam hal ini adalah wanita dewasa. Diri ideal yang terbentuk adalah menikah pada usia yang tepat dengan pria pilihan. Nilai ideal bahwa wanita dewasa harus menikah ini, dipengaruhi oleh lingkungan, budaya, serta kondisi biologis dan psikologis. Kenyataannya, ketika wanita belum juga menikah pada usia yang sudah matang, maka kesadaran terhadap kondisi tersebut menjadi bagian dari konsep diri. Kesenjangan antara konsep diri dengan diri ideal ini lah yang memunculkan kecemasan. Berdasarkan paparan di atas, dalam penelitian ini akan ditelaah kecemasan yang dirasakan wanita yang telat menikah. Penelitian ini diharapkan dapat memberikan gambaran bagi wanita yang telat menikah dan masyarakat umum tentang kecemasan yang muncul dan dinamikanya.

\section{METODE}

Penelitian ini menggunakan metode kualitatif dengan pendekatan studi kasus.

Renyep Proborini, Fakultas Psikologi Universitas Muhammadiyah Lampung, Email: rproborinini66@gmail.com

Gilang Sukma Lestari, Fakultas Psikologi Universitas Muhammadiyah Lampung. Khairani, Fakultas Psikologi Universitas Muhammadiyah Lampung 


\section{KECEMASAN PADA WANITA YANG TELAT MENIKAH DALAM PERSPEKTIF PERSON CENTERED THERAPY}

Tujuan dari penelitian ini adalah mendapatkan gambaran tentang kecemasan yang dialami oleh wanita telat menikah dari perspektif teori Person Centered Therapy. Sebagai subyek penelitian adalah tiga orang wanita berusia 28-30 tahun yang belum menikah. Metode pengumpulan data dilakukan dengan wawancara dan observasi. Untuk menjaga kredibilitas data, dilakukan wawancara terhadap pihak ketiga, yaitu orang yang memahami subyek. Unit analisis dari penelitian ini adalah kecemasan pada wanita usia 28-30 tahun yang belum menikah.

\section{HASIL}

$$
\text { Masing-masing subyek memiliki }
$$

kekhasan dalam memaknai pengalaman belum menikah. Berdasarkan teori Person Centered Therapy, gambaran mengenai dinamika kecemasan ketiga subyek difokuskan pada pengalaman organisme, kesadaran dan ketidaksadaran, konsep diri, diri ideal dan kecemasan.

\section{Subyek 1 (S1)}

S1 seorang wanita berusia 30 tahun, berpendidikan Sarjana, bekerja sebagai wirausaha.

S1 memiliki pengalaman organisme bersama keluarga besar yaitu kebersamaan, keakraban, kasih sayang, perhatian dan keterbukaan. Keluarga besar S1 akrab, satu sama lain. Mereka biasa berkumpul bersama. Sewaktu berumur 3 tahun hingga SD, S1 tinggal bersama kakek nenek. S1 mengenal disiplin ketat mengenai kebersihan, cara makan, harus makan sayur, sholat 5 waktu dan sholat sunah, serta tidak boleh bermain di luar. Teman-teman S1, teman paman-paman, semua bermain ke rumah. Rumah menjadi pusat keluarga serta pusat teman-teman. Keluarga besar dan diri S1 terbuka terhadap teman-teman S1. S1 percaya diri untuk menjalin hubungan dengan temantemannya. la memiliki banyak teman dengan kualitas hubungan yang baik. S1 tertarik dengan lawan jenis, beberapa kali memiliki pacar atau hanya pendekatan dengan lawan jenis, dan kemudian putus karena pacarnya beralih ke wanita lain.

Baginya, orang paling penting yang ia sangat sayangi adalah ayah, ibu, kakek, nenek. Hal ini dinyatakan oleh S1 dengan penekanan

"kakek-nenek saya dan ayah ibu saya, 4 orang itu sangat-sangat penting dalam hidup saya dan ada 2 orang laki-laki yang cintanya penuh untuk saya dan saya mencintai mereka sangat teramat penuh. Dan ada 2 orang wanita yang lewat doadoa merekalah hidup saya jadi mudah."

Perasaan cinta yang sangat besar dari S1 terhadap kakek dan ayahnya menjadi konflik, manakala S1 sangat kecewa terhadap mereka berdua karena keduanya pernah menikah lagi dengan wanita lain selain istri alias nenek dan

Renyep Proborini, Fakultas Psikologi Universitas Muhammadiyah Lampung, Email: rproborinini66@gmail.com

Gilang Sukma Lestari, Fakultas Psikologi Universitas Muhammadiyah Lampung. Khairani, Fakultas Psikologi Universitas Muhammadiyah Lampung 


\section{KECEMASAN PADA WANITA YANG TELAT MENIKAH DALAM PERSPEKTIF PERSON CENTERED THERAPY}

ibu S1. Kekecewaannya ia rasakan hingga sekarang, seperti pernyataannya "saya ga bisa terima sampai sekarang". Hal serupa kemudian juga dilakukan oleh semua pamannya. S1 menggeneralisir pengalaman organisme ini, bahwa laki-laki Indonesia tidak memiliki komitmen terhadap istri. S1 tidak menyadari bahwa masih banyak suami/pria lain yang memiliki komitmen terhadap istrinya. la mengabaikan fakta tersebut karena tidak sesuai dengan keyakinannya.

S1 memandang dirinya sebagai orang yang memiliki prestasi, cerdas, mandiri, bersih, mudah bergaul. Di sisi lain, dari berbagai pengalaman organismenya, S1 memiliki keinginan untuk studi ke luar negeri, menikah di usia 30 tahun, menikah dengan pria "bule". S1 menyukai pria yang cerdas, bersih dan setia. Keinginannya untuk memiliki dan mencapai sesuai dengan kriteria tersebut, merupakan diri idealnya, atau apa yang ia inginkan terhadap dirinya.

S1 pernah merasa dekat dengan seorang pria asal Inggris yang kebetulan memiliki kegiatan di Lampung untuk satu bulan. Beberapa kali S1 bertemu. Meskipun ia tidak dapat berkomunikasi secara baik karena keterbatasan bahasa Inggrisnya, ia menyatakan bahwa ia memiliki hubungan special dengan pria tersebut. Hubungan tersebut berakhir, karena pria bule ini menikah dengan wanita senegaranya, setelah kembali ke negara asalnya.

Saat ini, S1 menjalin hubungan jarak jauh dengan pria Indonesia yang tinggal dan bekerja di propinsi lain. Komunikasi lebih banyak melalui social media. Beberapa kali mereka bertemu langsung. Hubungan mereka telah berlangsung selama 4 tahun. S1 menghindari komunikasi yang mengarah pada pernikahan. Dari pengalamannya menyaksikan para suami yang menduakan istri, membuat S1 melakukan antisipasi bahwa bila suatu ketika ia menikah dan suaminya mau menikah lagi, maka ia meminta untuk bercerai.

Keadaan S1 yang belum menikah di usia 30 tahun ini, dalam persepsi S1 merupakan hal yang bermasalah, namun masih ringan. la dengan santai menanggapi pertanyaanpertanyaan dari lingkungan tentang kapan menikah. la tidak mudah terpengaruh oleh lingkungan, sebab ketika ia telah memiliki keyakinan, maka sulit untuk berubah.

\section{Subyek 2: S2}

S2 seorang wanita berusia 30 tahun, pendidikan SMA, pekerjaan wirausaha jasa salon. S2 berasal dari kota M di propinsi lain. Sejak SD ia tinggal di Bandarlampung bersama ayah, ibu dan adiknya. Ketika SMP, ibunya meninggal dan dimakamkan di Natar, Lampung Selatan. Kehilangan ibu menyebabkan S2

Renyep Proborini, Fakultas Psikologi Universitas Muhammadiyah Lampung, Email: rproborinini66@gmail.com

Gilang Sukma Lestari, Fakultas Psikologi Universitas Muhammadiyah Lampung. Khairani, Fakultas Psikologi Universitas Muhammadiyah Lampung 


\section{KECEMASAN PADA WANITA YANG TELAT MENIKAH DALAM PERSPEKTIF PERSON CENTERED THERAPY}

sangat sedih. la memiliki hubungan yang dekat dengan ibu.

Tidak lama setelah ibunya meninggal, ayahnya kembali ke kota $\mathrm{M}$ dan tinggal bersama abang S2. Sedangkan S2 dan adiknya tetap tinggal di Bandarlampung ikut pamannya untuk melanjutkan sekolah hingga SMA. Setelah lulus SMA, ia kembali ke kota $M$ dan tinggal bersama ayahnya. Ketika itu ia menjalin hubungan dekat dengan seorang pria selama 3 tahun namun tidak berlanjut. Orang tua pihak laki-laki tidak setuju karena masa depan S2 tidak jelas dan orang tua si lelaki sdh memiliki calon bagi anaknya. S2 didatangi dan dilabrak oleh ibu pihak laki-laki agar menjauhi anaknya. S2 sangat sakit hati dan memilih menghindar dengan bekerja di Malaysia hingga bertahan 8 tahun. Ketika kontrak kerja telah selesai, ia memutuskan untuk tinggal di Bandarlampung agar dekat dengan makam ibunya serta untuk melupakan mantan pacar.

S2 sibuk dengan pekerjaannya, mandiri secara emosi dan ekonomi, pendiam, tertutup, relasi terbatas, dan menghindari konflik. Setelah pengalamannya putus hubungan dengan pacarnya 9 tahun yang lalu, ia belum pernah pacaran lagi. S2 ingin menikah usia 22 tahun, dan sekarang ia berusia 30 tahun. Pada dasarnya ia kesulitan untuk menjalin relasi dengan cepat dan akrab, termasuk dengan lawan jenis. Waktunya sebagian besar ia habiskan untuk bekerja.
S2 rindu dengan ayahnya, namun tidak berani kembali ke kota $M$, karena ia akan teringat dengan kenangan pahitnya dilabrak ibu si lelaki dan sulit melupakan mantan pacarnya. Rasa sakit hati masih dirasakannya hingga sekarang. la juga tidak sanggup melihat kesedihan ayahnya bila melihat dirinya belum menikah.

S2 berupaya melupakan kenangan pahit tersebut dengan bekerja. Keinginan menikah tetap ada, namun ia abaikan. Harapan keluarga yang terlontar dari pertanyaanpertanyaan seputar pernikahan, menyebabkan S2 kembali merasa sedih. Apalagi ketika adiknya akan menikah dalam waktu dekat, semakin banyak yang bertanya kepadanya. Pernyataan "sedih banget sih kamu", " kamu baik banget sih, kok kamu mau dilengkahin". Awalnya ia sudah siap secara emosi, namun karena komentar-komentar tersebut menyebabkannya sedih.

S2 sadar bahwa meskipun ia ingin menikah tapi karena calon belum ada, maka keinginannya tidak dapat terpenuhi. S2 juga menyadari bahwa lingkungan keluarga mengharapkan dirinya untuk segera menikah. Namun demikian harapan lingkungan tersebut tidak sepenuhnya ia jadikan bagian dari diri. S2 tidak berupaya secara kuat untuk mencari pasangan dengan berbagai cara. la tidak mau dijodohkan, dan hanya mau melalui cara perkenalan sewajarnya langsung dengan

Renyep Proborini, Fakultas Psikologi Universitas Muhammadiyah Lampung, Email: rproborinini66@gmail.com

Gilang Sukma Lestari, Fakultas Psikologi Universitas Muhammadiyah Lampung. Khairani, Fakultas Psikologi Universitas Muhammadiyah Lampung 


\section{KECEMASAN PADA WANITA YANG TELAT MENIKAH DALAM PERSPEKTIF PERSON CENTERED THERAPY}

dirinya. Lelaki yang ia idamkan adalah lelaki yang kebapakan dan bertanggungjawab. S2 cukup dapat menerima diri bahwa pada kenyataannya ia belum memiliki calon pendamping.

\section{Subyek 3: S3}

S3 berusia 28,5 tahun, pendidikan SMA, bekerja sebagai petugas kebersihan di sebuah perguruan tinggi di Bandarlampung. la pernah kuliah hingga semester $\mathrm{V}$ di perguruan tinggi negeri di Bandarlampung.

Berbagai pengalaman organisme pada S3, banyak yang disadarinya, yang kemudian membentuk konsep dirinya. Selama bergaul dengan lingkungan, S3 menyadari adanya tuntutan dan harapan dari lingkungan terhadap pasangan yang menikah, yaitu kemapanan ekonomi, pendidikan tinggi, Standard dari lingkungan tersebut, ia jadikan standard bagi dirinya. Sedangkan kondisi S3 hanya tamat SMA, pekerjaannya yang sederhana dan kondisi ekonomi yang belum mapan.

S3 pendiam, labil secara emosi, sensitive, sering mengurung diri di kamar, tertutup terhadap keluarga dan lingkungan, kurang percaya diri. Setiap kali berkenalan dengan laki-laki yang mengarah pada hubungan serius, kecemasannya tinggi. Perasaannya yang berlebihan tercermin dari pernyataannya "... saya masih belum siap, selalu belum siap, belum siap, menunda, menunda, menunda sampai sekarang umur 28 tahun ...." S3 merasa tidak pantas untuk menikah, cemas menyesuaikan diri dengan mertua, dan cemas bila suami berubah sikap. Kenyataannya, secara fisik ia cukup cantik dan menarik. Secara financial, ibunya pensiunan PNS dan ada tanggungan seorang adik. Artinya, keluarganya bukan sama sekali tidak berpendapatan.

Kecemasan S3 bertambah dengan pertanyaan dari keluarga dan teman mengenai kesendiriannya. la sedih dan frustrasi atas kondisinya. Atas dorongan kakak ipar, S3 bergabung dengan komunitas Waris yaitu Wanita Perindu Surga yang beraktivitas dalam kajian agama. Setelah ia bekerja, ia sedikit lebih ceria dibandingkan sebelum bekerja.

\section{DISKUSI}

Berdasarkan dinamika permasalahan pada ketiga subyek dapat ditarik benang merah di antara ketiganya. Adanya pengalamanpengalaman organisme, yang mana para subyek berinteraksi dengan lingkungan. Pengalaman tersebut, didengar, dilihat dan rasai oleh diri. Sebagian dari pengalaman tersebut disadari dan sebagian diabaikan atau diubah. Pengalaman tersebut meliputi sejumlah peristiwa bersama keluarga, teman, mantan pacar, dan lingkungan lain. Pemaknaan terhadap peristiwa tersebut kemudian menuntun para subyek dalam menyikapi masalah belum menikah. Para subyek merasakan bahwa belum

Renyep Proborini, Fakultas Psikologi Universitas Muhammadiyah Lampung, Email: rproborinini66@gmail.com

Gilang Sukma Lestari, Fakultas Psikologi Universitas Muhammadiyah Lampung. Khairani, Fakultas Psikologi Universitas Muhammadiyah Lampung 


\section{KECEMASAN PADA WANITA YANG TELAT MENIKAH DALAM PERSPEKTIF PERSON CENTERED THERAPY}

menikah merupakan masalah lebih banyak karena harapan dari lingkungan.

Berdasarkan pengalaman, para subyek juga membentuk diri ideal, sebuah acuan keinginan yang ingin dicapai. Sebagian memiliki diri ideal yang berjarak cukup jauh dengan kenyataan atau konsep diri, dan yang lain dekat. Jauh dekatnya jarak tersebut pada akhirnya menentukan tingkat kecemasan. Semakin jauh, subyek semakin cemas.

Penyelesaian permasalahan pada para subyek adalah dengan menyibukkan diri dengan pekerjaan (S1,S2), melupakan (S2) atau sedih (S3). Ketiga subyek belum melakukan upaya efektif untuk menyelesaikan masalahnya, ketika ada beberapa pengalaman yang tidak disadarinya.

\section{SIMPULAN \& SARAN}

Kecemasan karena belum menikah yang dialami oleh para subyek berada di level rendah, sedang, dan tinggi. Tinggi rendahnya level bergantung pada besar kecilnya kebutuhan untuk menikah, kesadaran tentang pengalaman yang dilalui, bagaimana subyek memandang dirinya dan bagaimana subyek menginginkan sesuatu. Pengakuan terhadap kemampuan diri turut berpengaruh terhadap level kecemasan. Masing masing subyek memilih pengalamannya secara khas sesuai dengan gambaran dirinya. S1 memiliki keterikatan kuat dengan keluarganya, percaya diri dan mandiri, kurang memiliki komitmen untuk menikah. S2 sakit hati dengan masa lalu, belum siap untuk menjalin hubungan baru dengan lawan jenis, namun ia mandiri dan cukup dapat mengabaikan kebutuhannya untuk menikah. S3 kurang percaya diri, sensitif dan labil emosinya sehingga banyak mengambil standard dari lingkungan menjadi standard bagi dirinya. S3 ingin menikah namun ia sangat cemas dengan konsekuensinya.

Saran bagi penelitian yang akan datang adalah melanjutkan penelitian ini terhadap subyek yang sama, yang bertujuan untuk melihat efektifitas terapi Person Centered Therapy dalam menurunkan tingkat kecemasan karena telat menikah, serta kurang berkembangnya diri karena pengalamanpengalaman yang diabaikan. Tujuan tersebut dapat tercapai dengan menawarkan untuk memberikan terapi kepada ketiga subyek serta mengukur hasilnya.

Renyep Proborini, Fakultas Psikologi Universitas Muhammadiyah Lampung, Email: rproborinini66@gmail.com

Gilang Sukma Lestari, Fakultas Psikologi Universitas Muhammadiyah Lampung. Khairani, Fakultas Psikologi Universitas Muhammadiyah Lampung 


\section{KECEMASAN PADA WANITA YANG TELAT MENIKAH DALAM PERSPEKTIF PERSON CENTERED THERAPY}

\begin{tabular}{|c|c|c|}
\hline $\begin{array}{l}\text { Pengalaman organisme yang disadari S1 } \\
\text { - Keluarga sangat penting, sangat mencintai } \\
\text { kakek-nenek-ayah-ibu } \\
\text { - Kakek \& ayah pernah menikah lagi, menduakan } \\
\text { istri } \\
\text { - Usia 2-3 tahun pernah kambuh asma hingga } \\
\text { dinyatakan meninggal namun beberapa menit } \\
\text { kemudian bangun lagi. Sejak itu S1 dirawat oleh } \\
\text { kakek nenek yang orang kesehatan. } \\
\text { - Penanaman disiplin oleh kakek nenek yang } \\
\text { ketat tentang kebersihan, aturan bermain, } \\
\text { makan, ibadah } \\
\text { - Keluarga besar sangat terbuka terhadap teman- } \\
\text { teman S1 } \\
\text { - Memiliki hubungan baik dengan banyak teman } \\
\text { - Sebagian besar temannya, laki-laki. Tidak terpikir } \\
\text { untuk tertarik pada banyak teman laki-lakinya. } \\
\text { - Pernah pacaran sewaktu SMP, SMA. Putus } \\
\text { karena semuanya selingkuh dengan teman } \\
\text { wanita S1 } \\
\text { - Usia } 24 \text { tahun pacaran dengan laki-laki Inggris. } \\
\text { Komunikasi tidak lancar karena keterbatasan } \\
\text { kemampuan bahasa Inggrisnya dan si laki-laki } \\
\text { tersebut menikah dengan wanita Inggris } \\
\text { - Banyak prestasi, cerdas } \\
\text { - Sudah } 4 \text { tahun terakhir pacaran jarak jauh } \\
\text { dengan pria berusia } 3 \text { tahun di bawahnya. S1 } \\
\text { menghindari komitmen, sementara pacarnya } \\
\text { sudah mengarah hubungan yang serius } \\
\text { tanggungjawabnya } \\
\text { meluarga besar dan teman bertanya kapan } \\
\text { Secara financial, ibu dan adik menjadi }\end{array}$ & $\begin{array}{l}\text { Konsep diri } \\
\text { Cerdas, wawasan } \\
\text { luas,percaya diri, } \\
\text { terbuka, mudah } \\
\text { bergaul, tertarik pada } \\
\text { lawan jenis, bersih, } \\
\text { mandiri, kukuh } \\
\text { pendirian, dihargai } \\
\text { dan dicintai keluarga, } \\
\text { usia } 30 \text { tahun } \\
\\
\text { Diri ideal } \\
\text { Cerdas, wawasan } \\
\text { luas,percaya diri, } \\
\text { terbuka, mudah } \\
\text { bergaul, tertarik pada } \\
\text { lawan jenis, bersih, } \\
\text { mandiri, kukuh } \\
\text { pendirian, dihargai } \\
\text { dan dicintai keluarga. } \\
\text { Ingin menikah di usia } \\
\text { antara 28-30 tahun, } \\
\text { Ingin kuliah di luar } \\
\text { negeri, menikah } \\
\text { dengan laki-laki bule } \\
\text { Laki-laki idaman } \\
\text { adalah cerdas, bersih, } \\
\text { setia }\end{array}$ & $\begin{array}{l}\text { Ketidaksadaran S1 } \\
\text { - Banyak laki-laki } \\
\text { Indonesia di } \\
\text { sekitarnya yang } \\
\text { setia } \\
\text { - Pacar bulenya } \\
\text { meninggalkannya } \\
\text { dan menikah } \\
\text { dengan wanita lain } \\
\text { - Keluarga menjadi } \\
\text { pusat diri dan } \\
\text { terpenuhinya } \\
\text { kebutuhan cinta \& } \\
\text { kasih sayang dari } \\
\text { keluarga } \\
\text { Kesulitan dalam } \\
\text { mengubah pola pikir: } \\
\text { teman laki-laki } \\
\text { selamanya menjadi } \\
\text { teman. Tidak bisa } \\
\text { jadi pacar. Laki-laki } \\
\text { Indonesia suka } \\
\text { selingkuh, laki-laki } \\
\text { bule setia } \\
\text { - Kesulitan } \\
\text { berkomitmen } \\
\text { dengan laki-laki } \\
\text { karena kesulitan } \\
\text { untuk mengubah } \\
\text { orientasi hidup. } \\
\text { Bahwa pusat } \\
\text { keluarga akan } \\
\text { bergeser jika } \\
\text { menikah. Serta } \\
\text { kekecewaan } \\
\text { terhadap para pria di } \\
\text { keluarga besarnya } \\
\text { yang selingkuh } \\
\text { ala }\end{array}$ \\
\hline
\end{tabular}

\section{Diagram 1. Dinamika Permasalahan S1}

Renyep Proborini, Fakultas Psikologi Universitas Muhammadiyah Lampung, Email: rproborinini66@gmail.com

Gilang Sukma Lestari, Fakultas Psikologi Universitas Muhammadiyah Lampung. Khairani, Fakultas Psikologi Universitas Muhammadiyah Lampung 


\section{KECEMASAN PADA WANITA YANG TELAT MENIKAH DALAM PERSPEKTIF PERSON CENTERED THERAPY}

\begin{tabular}{|c|c|c|}
\hline $\begin{array}{l}\text { Pengalaman yang disadari oleh } \\
\text { S2 } \\
\text { - Setelah lulus SMA, pernah } \\
\text { pacaran } 3 \text { tahun, putus karena } \\
\text { ditentang orang tua lelaki } \\
\text { - la dilabrak oleh ibu si lelaki, } 9 \\
\text { tahun yang lalu, dan sakit hati } \\
\text { hingga sekarang } \\
\text { - la ingin menikah usia } 22 \text { tahun } \\
\text { - Kerja di Malaysia selama } 8 \\
\text { tahun untuk menjauhi pacarnya } \\
\text { - Teman terbatas jumlahnya, } \\
\text { namun berusaha menjaga } \\
\text { hubungan baik } \\
\text { - Sejak SMP, ibu meninggal } \\
\text { dunia, sangat sedih } \\
\text { - Keluarga dan teman bertanya } \\
\text { tentang pernikahan } \\
\text { - Tinggal di Bandarlampung untuk } \\
\text { melupakan kenangan pahit, } \\
\text { menghindari ayah dan keluarga } \\
\text { yang mengharapkan dirinya } \\
\text { menikah, dekat dengan (makam) } \\
\text { ibunya. }\end{array}$ & 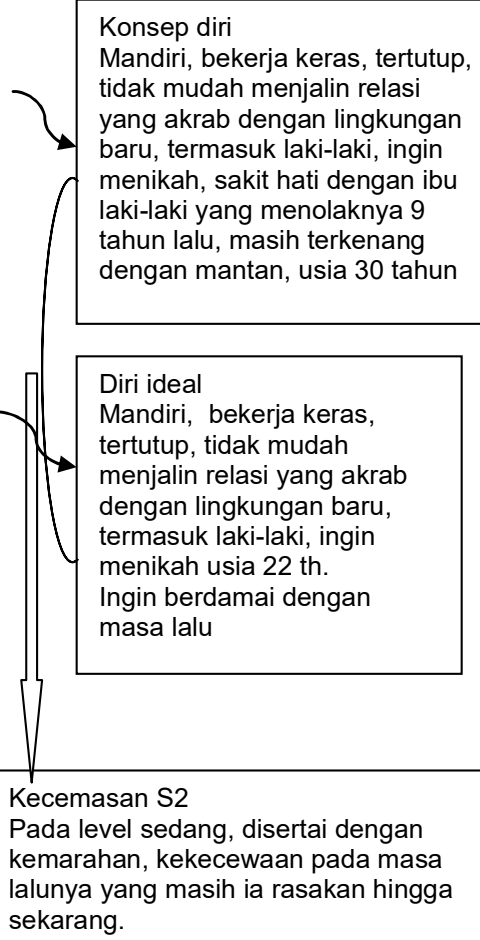 & $\begin{array}{l}\text { Pengalaman yang tidak } \\
\text { disadari } \\
\text { - Membutuhkan teman } \\
\text { untuk curhat agar dapat } \\
\text { mengurai rasa sakit } \\
\text { hatinya } \\
\text { - Kesulitan } \\
\text { mengekspresikan } \\
\text { perasaan sedih dan sakit } \\
\text { hatinya }\end{array}$ \\
\hline
\end{tabular}

Diagram 2. Dinamika Permasalahan S2

Renyep Proborini, Fakultas Psikologi Universitas Muhammadiyah Lampung, Email: rproborinini66@gmail.com

Gilang Sukma Lestari, Fakultas Psikologi Universitas Muhammadiyah Lampung. Khairani, Fakultas Psikologi Universitas Muhammadiyah Lampung 


\section{KECEMASAN PADA WANITA YANG TELAT MENIKAH DALAM PERSPEKTIF PERSON \\ CENTERED THERAPY}

Pengalaman S3 yang disadari
- Berasal dari keluarga secara
financial, kurang
- Banyak terpengaruh oleh
lingkungan.
- Lingkungan mengharapkan
agar orang yang menikah
sudah mapan secara ekonomi,
pendidikan tinggi, pekerjaan
yang baik.
- Tertutup dan sulit untuk
berteman. Banyak mengurung
diri di kamar
- Sadar bila kecemasan tinggi
- Cemas untuk menyesuaikan diri
dengan suami dan mertua.
- Komitmen rendah, setiap kali
kenalan dengan laki-laki, S3
akan menjauh dan menghilang
bila hubungan ke arah serius
- Menetapkan syarat bagi laki-laki
- Ikut kajian agama

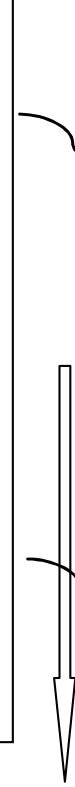

Konsep diri

Kurang percaya diri

berkaitan dengan

pendidikan, ekonomi,

pekerjaan, cemas dengan

kehidupan berumahtangga,

sulit adaptasi, tertutup,

berpikir negative terhadap

berbagai pengalaman,

usia 28 tahun diri di kamar

- Cemas untuk menyesuaikan diri

bila hubungan ke arah serius

- Menetapkan syarat bagi laki-lak

- Ikut kajian agama

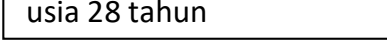

Pengalaman S3 yang tidak disadari

Sumber masalah adalah diri sendiri. Dirinya cantik,

tingkat ekonomi orang tua

yang cukup, bukan sama

sekali tidak berpenghasilan

Diagram 3. Dinamika permasalahan S3

Renyep Proborini, Fakultas Psikologi Universitas Muhammadiyah Lampung, Email: rproborinini66@gmail.com

Gilang Sukma Lestari, Fakultas Psikologi Universitas Muhammadiyah Lampung. Khairani, Fakultas Psikologi Universitas Muhammadiyah Lampung 


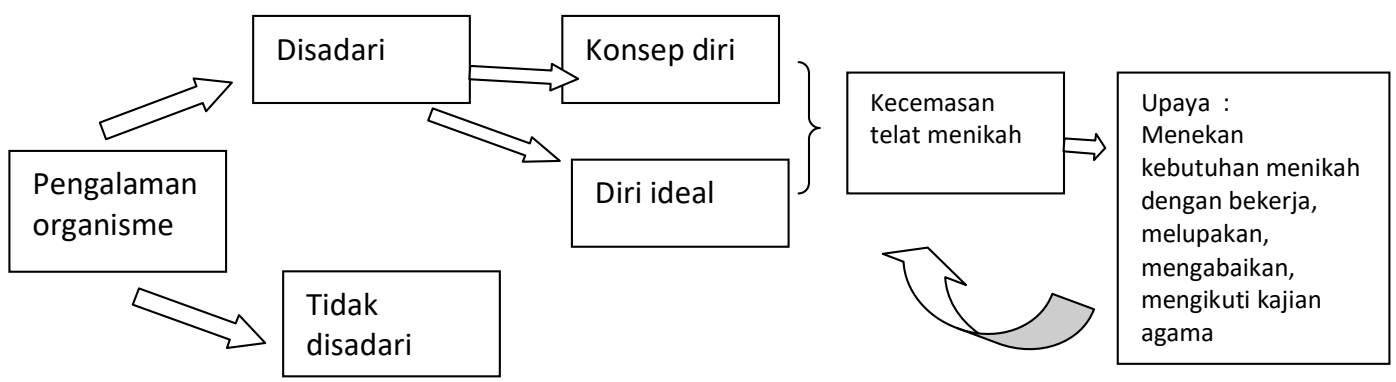

Diagram4. Dinamika Penyelesaian Permasalahan Subjek

DAFTAR PUSTAKA

Adhim, M. F., \& Omar, N. (2014). Saatnya untuk menikah. Aras Mega.

Agustian, Hesti., 2013, Gambaran Kehidupan Pasangan yang Menikah di Usia Muda di Kabupaten Dharmasraya, Jurnal Spektrum. PLS, Vol.1 no.1, April

Anderson, H. (2001). Postmodern collaborative and person-centred therapies: what would Carl Rogers say?. Journal of family therapy, 23(4), 339-360.

Fadlyana., Eddy., Larasaty. Shinta., 2009, Pernikahan Usia Dini dan Permasalahannya, Jurnal Sari Pediatri, vol.11 no.2, Agustus

Feist, J., Feist, GJ., Teori Kepribadian, edisi 7. Jakarta: Salemba Humanika 2010

Ma'arif. Fitria., 2018, Hubungan antara Tingkat Pengetahuan \& Sosial Budaya dengan Sikap Remaja Terkait Pendewasaan Usia Perkawinan, Jurnal Biometrika \& Kependudukan, Vol.7, no.1, Juli.

Kusdwiratri S. (2011). Psikologi Keluarga. Bandung: Alumni

Renyep Proborini, Fakultas Psikologi Universitas Muhammadiyah Lampung, Email: rproborinini66@gmail.com

Gilang Sukma Lestari, Fakultas Psikologi Universitas Muhammadiyah Lampung. Khairani, Fakultas Psikologi Universitas Muhammadiyah Lampung
Santrock, John W., (2002). Life-span

Development Perkembangan Masa Hidup. Jilid 2. Jakarta: Erlangga 